\title{
CLASSES OF OPERATORS RELATED TO $m$-ISOMETRIC OPERATORS
}

\author{
Salah Mecheri And Sid Ahmed Ould Ahmed Mahmoud
}

\begin{abstract}
Isometries played a pivotal role in the development of operator theory, in particular with the theory of contractions and polar decompositions and has been widely studied due to its fundamental importance in the theory of stochastic processes, the intrinsic problem of modeling the general contractive operator via its isometric dilation and many other areas in applied mathematics. In this paper we present some properties of $n$-quasi- $(m, C)$-isometric operators. We show that a power of a $n$-quasi- $(m, C)$-isometric operator is again a $n$-quasi- $(m, C)$-isometric operator and some products and tensor products of $n$-quasi- $(m, C)$-isometries are again n-quasi$(m, C)$-isometries.
\end{abstract}

Mathematics subject classification (2010): 47B99, 47A05.

Keywords and phrases: $m$-isometries, $n$-quasi- $m$-isometries, $(m, C)$-isometries, $n$-quasi- $(m, C)$-isometries.

\section{REFERENCES}

[1] B. Abdullah T. Le, The structure of $m$-isometric weigted shift operator, Operators and Matrices, vol 10, Number 2 (2016), 319-334.

[2] J. AGLeR AND M. STANKus, $m$-Isometric transformations of Hilbert space I, Integral Equations and Operator Theory, 21(1995), 383-429.

[3] J. Agler And M. StAnKus, $m$-Isometric transformations of Hilbert space. II, Integral Equ.Oper. Theory 23(1), 1-48 (1995).

[4] J. AgLeR AND M. StAnKus, $m$-Isometric transformations of Hilbert space. III, Integral Equ. Oper. Theory 24(4), 379-421 (1996).

[5] M. F. Ahmadi, S. Yarmahmoodi and K. Hedayatian, Perturbation of $(m, p)$-isometries by nilpotent operators and their supercyclicity, Oper. Matrices 11(2017), 381-387.

[6] F. BAYART, m-Isometries on Banach spaces, Math. Nachr. 284(2011), 2141-2147.

[7] T. Bermúdez, C. D. Mendoza and A. Martinón, Powers of $m$-isometries, Studia Mathematica 208 (3) (2012).

[8] T. Bermúdez, A. Martinón, V.Mvller, J.A. NodA, Perturbation of $m$-Isometries by Nilpotent Operators, Abstract and Applied Analysis, Volume 2014, Article ID 745479, 6 pages.

[9] T. BermúdeZ, A. MARTINón, J.A. NODA, An isometry plus a nilpotent operator is an $m$-isometry. Applications, J. Math. Anal. Appl. 407(2),(2013). 505-512.

[10] T. Bermúdez, A. Martinón, J.A. Noda, Products of $m$-isometries, Linear Algebra and its Applications 438 (2013) 80-86.

[11] M. Сhō, E. Ko And J. E. Lee, On $(m, C)$-Isometric Operators, Complex Anal. Oper. Theory 10 (2016), 1679-1694.

[12] M. Chō, J.E. Lee And H. Motoyoshia, On [m,C]-Isometric Operators, Filomat 31:7 (2017), 2073-2080.

[13] B. P. DugGaL, Tensor product of n-isometries, Linear Algebra and its Applications 437 (2012),307318.

[14] S. R. Garcia And M. Putinar, Complex symmetric operators and applications, Trans. Amer. Math. Soc. 358(2006), 1285-1315.

[15] S. R. Garcia, E. Prodan And M. Putinar, Mathematical and physical aspects of complex symmetric operators, J. Phys. A: Math. Theory 47(2014) 353001 (54pp).

[16] C. Gu, Structures of left $n$-invertible operators and their applications, Studia Mathematica 226 (3) (2015). 
[17] K. Hedayatian and A. M. Moghaddam, Some properties of the spherical $m$-isometries, J. Operator 79:1(2018), 55-77.

[18] J. Kyu Han, H. Youl LeE AND W. Young LeE, Invertible completions of $2 \times 2$ upper triangular operator matrices, Proc. Amer. Math. Soc. 128 (1999), 119-123.

[19] S. Mecheri AND T. PRASAD, On n-quasi-m-isometric operators, Asian-European Journal of Mathematics 9 (2016), (8 pages).

[20] S. Mecheri And S. M. Patel, On quasi-2-isometric operators, Linear and Multlinear Algebra (2017), https://doi.org/10.1080/03081087.2017.1335283.

[21] S. M. PATEL, 2 -isometric operators, Glas. Mat. 37 (57) (2002), 141-145.

[22] S. M. PATEL, A note on quasi-isometries, Glas. Mat. 35 (55) (2000) 307-312.

[23] S. M. PATEL, A note on quasi-isometries II, Glas. Mat. 38 (58) (2003) 111-120.

[24] O. A. M. Sid Ahmed, M. СhŌ AND J. E. LeE, On n-quasi- $(m, C)$-isomtric operators, Linear and Multilinear Algebra, https://doi.org/10.1080/03081087.2018.1524437.

[25] O. A. M. Sid Ahmed, M. Chō And J. E. LeE, On ( $m, C)$-Isometric Commuting Tuples of Operators on a Hilbert Space, Results Math (2018) 73:51. 